\title{
Detecção de emissão espontânea de luz em ensaios de colimetria aplicados ao monitoramento de efluentes sanitários
}

\section{Spontaneous light emission in coliforms test applied to wastewater monitoring}

\author{
Samuel Ricardo dos Santos \\ Mestre em Engenharia Agrícola pela Universidade Estadual de Campinas (Unicamp). Pesquisador em Biofotônica Aplicada da Faculdade de Tecnologia da Unicamp \\ José Euclides Stipp Paterniani \\ Professor Doutor do Departamento de Água e Solo da Faculdade de Engenharia Agrícola da (Unicamp)
}

Cristiano de Mello Gallep

Professor Doutor do Departamento de Telecomunicações da Faculdade de Tecnologia da Unicamp.

Coordenador do Laboratório de Fotônica Aplicada (LaFA) da Unicamp

\section{Resumo}

No presente trabalho avaliou-se o potencial do emprego da técnica biofotônica ao monitoramento da qualidade microbiológica de efluentes sanitários, por meio da detecção de emissão ultrafraca de luz em testes envolvendo bactéria do grupo coliforme. Foram acompanhados os padrões de emissão de luz em câmara escura com o uso de efluente doméstico, antes e após tratamento, incubados em meio nutritivo à base de lactose e lauril triptose. O controle foi efetuado com o uso de cepa de Escherichia coli (ATCC 25.922), tendo seu crescimento sido monitorado por emissão de luz em câmara escura com fotomultiplicador acoplado. Os dados demonstraram que o monitoramento microbiológico pode ser efetuado por meio técnica biofotônica, podendo ser aplicado, com respostas rápidas, ao monitoramento microbiológico de efluentes, por meio de testes envolvendo coliformes.

Palavras-chave: esgoto sanitário; coliformes; luminescência; monitoramento.

\section{Abstract}

The spontaneous light emission of living systems emerge as a promising methodology that applied to microbiological in monitoring water can lead to short-term analysis. The present study evaluated the potential of biophoton measurements applied to wastewater monitoring by using ultraweak light emission in coliform tests. The procedure is based on photon-counting measurements inside a dark-chamber, of wastewater samples, before and after treatment, inoculated in nutrient presence/absence medium (lactose and lauryl triptose broth). Strain of Escherichia coli (ATCC 25,922) was used in control tests by monitoring the light emission inside a dark-chamber with an acoplade photomultiplier. The data showed that microbiological monitoring can be done by photon-counting in real-time applied to microbiological wastewater monitoring using coliform test.

Keywords: wastewater; coliforms; luminescence; monitory.

\section{Introdução}

As bactérias do grupo coliformes têm sido amplamente empregadas no monitoramento da qualidade da água, sendo Escherichia coli o micro-organismo indicador mais preciso de contaminação fecal. Os métodos atuais de detecção apresentam, no mínimo, 18 horas para obtenção de resultados, sendo que em procedimentos tais como a técnica dos tubos múltiplos, podem chegar até 48 horas para análise conclusiva. A importância de uma rápida detecção de coliformes e Escherichia coli aplicada à qualidade e segurança da água torna-se necessária (MATHEW; ALAGESAN; ALOCIJA, 2004), e a técnica biofotônica apresenta-se como metodologia promissora do ponto de vista operacional e econômico, dada a constante geração de efluentes sanitários em todo planeta.

O fenômeno da emissão ultrafraca de luz foi reportado pela primeira vez na década de 1920 por Alexander Gurwitsch. Esse pesquisador demonstrou que a emissão de luz espontânea em uma célula promovia a divisão celular de outra célula contígua, fenômeno este denotado como radiação mitogenética, ou seja, radiação gerada em mitoses, com 
intensidade de algumas dezenas de fótons por segundo e comprimentos de onda variando de 200 a $300 \mathrm{~nm}$ (RAHN, 1935). Posteriormente, o físico Fritz A. Popp introduziu o termo "biofóton" para expressar a origem e o caráter quântico da fraca emissão de luz, emitida por organismos vivos abrangendo a região do espectro visível e próximo a este (POPP, 2000). Esse fenômeno, com intensidade de $10^{1}$ a $10^{3}$ fótons. $\mathrm{cm}^{-2} \cdot \mathrm{s}^{-1}$, é encontrado em compostos orgânicos em conjunto com a atividade dos sistemas biológicos e está intimamente relacionado com as condições metabólicas dos organismos (CHANG; FISCH; POPP, 1998).

Ao longo de 30 anos de pesquisas aplicadas, o grupo liderado por Popp, além de outros pesquisadores, não só demonstrou a presença da emissão espontânea de luz em seres vivos, como descreveram as suas propriedades, com o desenvolvimento e a comprovação de hipóteses sobre as suas funções biológicas (BELOUSSOV; VOEIKOV; MARTYNYUK, 2007). Hoje se sabe que essa emissão correlaciona-se intrinsecamente com todas as atividades da vida do organismo, e que a luz emitida cumpre uma função biológica (BISCHOF, 2005).

A emissão espontânea de luz por micro-organismos já foi estudada com culturas de Pseudomonas fluorescens (NIKOLAEV, 2000a, 2000b), Paramecium caudatum (FELS, 2009), Escherichia coli (TRUSHIN, 2003a, 2004; TILBURY; QUICKENDEN, 1987, 1988), Serratia mercescens, Deinococcus radiodurans, Proteus vulgaris e Lactococcus lactis lactis (VOGEL; SÜSSMUTH, 1998a, 1998b, , 1999a, 1999b; VOGEL; GUO; SÜSSMUTH, 1998). Outros trabalhos discorrem sobre mecanismos de defesa dos micro-organismos quando submetidos ao estresse físico-químico (TILBURY, 1992) e à origem da emissão de luz (TRUSHIN, 2003b, 2003c, 2003d). Aplicações práticas com o uso dessas propriedades estão disponíveis com a medição da bioluminescência em micro-organismos com diversas finalidades, incluindo o uso da bactéria Escherichia coli como bioindicador aplicado ao monitoramento ambiental (RODA, et al, 2004), a análise da coerência dos fótons provenientes das células e a capacidade de distinguir os diversos comprimentos de onda eletromagnética (BUDAGOVSKY, 2005) e o estudo de comportamentos genéticos utilizando Escherichia coli como modelo (LAAGER, et al, 2009).

Estudos de mecanismos luminescentes já foram desenvolvidos para detecção de coliformes com o uso de substrato quimiluminescente, em que a reação ocorrendo com a enzima $\beta$-glucorosidase proveniente da bactéria Escherichia coli é acompanhada pela luminescência (MATHEW; ALAGESAN; ALOCIJA, 2004). Pesquisadores do Departamento de Saúde Ambiental da Escola de Saúde Pública da Universidade de Michigan propuseram um método de detecção por meio de mecanismos bioluminescentes provenientes de reações do ATP (adenosina trifosfato), mediante o isolamento da Escherichia coli, por meio da técnica de separação imunomagnética, sendo que o método exige a utilização de aparatos para promover o isolamento de bactéria e reagentes adicionais para a detecção da luminescência (LEE; DEININGER, 2004, MATHEW; ALAGESAN; ALOCIJA, 2004).
O presente trabalho teve como objetivo avaliar o potencial da técnica biofotônica aplicada ao monitoramento microbiológico de efluentes sanitários, em função da fóton-contagem, provenientes da atividade metabólica dos coliformes, quando incubados em meio nutritivo à base de lactose e lauril triptose.

\section{Metodologia}

\section{Amostras de efluente sanitário}

Os ensaios foram efetuados com amostras coletadas na estação de tratamento de esgoto localizada no Campo Experimental da Faculdade de Engenharia Agrícola da Universidade de Campinas (UNICAMP), Campinas, SP. As coletas de amostras foram efetuadas na entrada e na saída da estação de acordo com procedimentos descritos em Agudo (1988), com o intuito de aferir correlações entre os padrões de emissão espontânea de luz nos testes de coliformes totais e Escherichia coli como método aplicado ao monitoramento do tratamento de esgoto. As amostras de esgotos foram caracterizadas por meio das seguintes variáveis: $\mathrm{pH}$, fósforo, nitrogênio (nitrito, nitrato e amoniacal) oxigênio dissolvido (OD) e demanda química de oxigênio (DQO), todas elas avaliadas de acordo com Apha (1998).

\section{Meios de cultura}

Caldo presença/ausência com 29,5 g.L.-1 de lauril triptose, 22,37 g.L-1 de lactose, 7,37 g.L.-1 de cloreto de sódio, 4,05 de fosfato de sódio di-hidrogenado; 4,05 g...-1 de fosfato di-potássio hidrogenado, 0,147 g.. $\mathrm{L}^{-1}$ de lauril sulfato de sódio, 9 g.L.-1 "Lab-Lemco Powder" e 15 g.L.-1 de peptona. Meio EC com MUG contendo: 20,0 g. $\mathrm{L}^{-1}$ de triptona, 5,0 g. $\mathrm{L}^{-1}$ de lactose, 1,5 g.L.-1 de sais biliares, 4,0 g.L $\mathrm{L}^{-1}$ de di-fosfato de potássio, 1,5 g.L.-1 de monofosfato de potássio, 5,0 g.L-1 de cloreto de sódio, 0,05 g.L-1 de 4-metilumbeliferil- $\beta$-D-glicuronídio (MUG).

\section{Ensaios-controle com cepa Escherichia coli}

Os ensaios de controle positivo foram realizados com o uso de cepa padronizada Escherichia coli ATCC 25.922.

\section{Condições de crescimento}

Colônias de Escherichia coli foram retiradas da cultura armazenada e incubadas inicialmente em três tubos de ensaio, contendo $10 \mathrm{~mL}$ de meio nutritivo a $37^{\circ} \mathrm{C}$ pelo período de $1 \mathrm{~h}$ (overnight), permitindo que os microorganismos atingissem a fase estacionária. Esse procedimento permitiu o crescimento com densidade celular da ordem de $10^{10}-10^{12}$ células. $\mathrm{mL}^{-1}$. Após o crescimento das células, efetuou-se o estudo da cinética de crescimento da Escherichia coli, conforme Aneja (2004), por meio da medida da densidade ótica em espectrofotômetro com comprimento de onda fixado 
em 600 nm. Os parâmetros de controle foram: número de gerações $n$, tempo de geração $g$ medido em horas e taxa de crescimento R expressa em $\mathrm{h}^{-1}$, de acordo com Madigan et al (2003).

Em intervalos de 30 minutos, efetuou-se a medida do oxigênio dissolvido (OD) no meio pelo período de 6 horas com o uso de oxímetro para comparações entre o crescimento do micro-organismo, a depleção de oxigênio e as taxas de emissão de luz.

\section{Câmara de fóton-contagem e acessórios}

Para o acompanhamento dos padrões de fóton-contagem provenientes das amostras, o experimento foi conduzido com dispositivo de fóton-contagem desenvolvido por Gallep et al (2005), que consiste em câmara escura construída em aço inoxidável com válvula fotomultiplicadora acoplada (Hamamatsu's inegrated PMT H7360), placa de contagem (Hamamatsu's counting board M8784), sistema de controle de temperatura, por meio de fluxo contínuo de fluido pré-aquecido controlado por circuito eletrônico, sendo que o dispositivo apresenta taxa de ruído de escuro de $192 \pm 22$ contagem/10s (\#/10s)

\section{Testes biofotônicos com cepa de Escherichia coli}

Os ensaios foram realizados com cepa previamente incubada em meio $\mathrm{EC}$ e P/A, iniciando todos os experimentos com densidade ótica variando entre 1,26 e 1,62 (fase estacionária). Alíquotas de $5 \mathrm{~mL}$ da cultura do micro-organismo previamente crescido foram adicionadas a $45 \mathrm{~mL}$ de meio nutritivo previamente aquecido em banho-maria à $37^{\circ} \mathrm{C}$. Após a incubação da cepa, esta foi levada para a câmara de fóton-contagem na temperatura de $37^{\circ} \mathrm{C}$ e tempo de incubação de 24 horas utilizando-se o aparato experimental construído para o desenvolvimento dos testes.

\section{Testes biofotônicos com esgoto doméstico}

Em câmara de fluxo laminar, $100 \mathrm{~mL}$ das amostras de efluente eram assepticamente transferidos para $50 \mathrm{~mL}$ de caldo P/A, homogeneizando, o volume inoculado, totalizando $150 \mathrm{~mL}$. O volume inoculado foi conduzido para câmara de fóton-contagem com temperatura fixada em $35,5^{\circ} \mathrm{C}$. Após 24 horas, amostra positivas ( 5 $\mathrm{mL}$ ) eram retiradas da câmara de fóton-contagem e transferidas para $45 \mathrm{~mL}$ do meio EC com MUG para o desenvolvimento dos testes com coliformes termotolerantes, sendo a temperatura fixada em $44,5^{\circ} \mathrm{C}$.

\section{Testes paralelos de contagem de coliformes}

Para se obter a relação entre a densidade de coliformes presentes nas amostras e a emissão de luz, paralelamente aos testes biofotônicos foram realizados ensaios com coliformes de acordo com metodologia que emprega o uso do substrato cromogênico (APHA, 1998). Os resultados obtidos foram comparados com os dados de fóton-contagem, provenientes de todos os ensaios biofotônicos, obtendo-se o número mais provável de coliformes totais e Escherichia coli por $100 \mathrm{~mL}$ (NMP/100 mL) da cultura original.

\section{Análise dos resultados e tratamento estatístico}

Os resultados obtidos nos ensaios de fóton-contagem foram analisados com base nos perfis temporais de fóton-contagem com aquisição de dados a cada 10s e tempo de análise de 24 horas. Os resultados foram descritos pelos parâmetros estatísticos soma, média, mínimo, máximo e desvio padrão. Com o uso do programa matemático Origin Pro 8.0, foi efetuada análise dos comportamentos biofotônicos em função da média local (100 pontos adjacentes) de contagem, possibilitando realizar comparações entre os dados de contagem versus número mais provável de coliformes totais e Escherichia coli por $100 \mathrm{~mL}$ de amostra (\#/10s versus NMP/100 mL). Todos os experimentos foram realizados com cinco réplicas permitindo a análise da estabilidade dos comportamentos obtidos experimentalmente.

\section{Resultados e discussão}

\section{Medidas de ruído com meios de cultura}

Na Figura 1 são apresentados os padrões de emissão de luz provenientes dos meios de cultura, importantes para diferenciá-los do fóton-contagem proveniente das amostras biológicas testes controle com Escherichia coli e testes com amostras de esgoto sanitário envolvendo coliformes totais e Escherichia coli. Para o meio P/A, observa-se o aumento das taxas de fóton-contagem nos primeiros 40 minutos partindo de 658 \#/10 s de intensidade e atingindo pico 695 \#/10 s. Posteriormente, as taxas decaem estabilizando-se a partir de 7,2 h com taxas de fóton-contagem em torno de 241 \#/10 segundos com pequenas oscilações de $\pm 13 \# / 10$ s. O meio EC apresentou comportamento semelhante, no entanto com intensidades menores: taxa de fóton-contagem partindo de $276 \# / 10$ s, chegando a 328 \#/10 s, decaindo em seguida com tendência à estabilização.

Segundo Vogel e Süssmuth (1999b), os meios de cultura comumente utilizados para o cultivo de micro-organismos apresentam variedade de peptonas, açúcares e sais inorgânicos que, quando submetidos ao processo de esterilização, podem gerar moléculas capazes de produzirem quimiluminescência com intensidades que variam de acordo com a composição do meio de cultura utilizado.

Na Figura 1(b), verifica-se que, em média, o meio P/A apresentou taxa de 313 \#/10 s, com desvios de \pm 195 \#/10 s. Já o meio EC não apresentou grandes desvios entre os testes como ocorrido com o meio P/A, podendo notar que as médias foram semelhantes, e os desvios ficaram em torno de $\pm 33 \# / 10 \mathrm{~s}$.

Vogel e Süssmuth (1998a, 1998b, 1998b) obtiveram em seus experimentos comportamentos semelhantes aos da Figura 1(a). Os dados 
obtidos por aqueles pesquisadores revelaram que as emissões são acompanhadas por comprimentos de ondas variando de 200 a 800 nm, com $75 \%$ das ocorrências para faixas de 500 e $700 \mathrm{~nm}$ em que esta quimiluminescência é utilizada pelos micro-organismos no processo de crescimento ao longo do tempo.

\section{Comportamentos biofotônicos de Escherichia coli em meio $\mathrm{P} / \mathrm{A}$}

O perfil típico de evolução do crescimento da Escherichia coli em meio P/A, medido por meio de emissão de luz, é apresentado na Figura 2(a). Na Figura 2(b) é descrita a cinética de crescimento, por meio da medida da densidade ótica (DO) em espectrofotômetro a 600 nm, comparando-se essas medidas com os padrões biofotônicos do micro-organismo no processo de degradação do substrato ao longo das sete primeiras horas de ensaio. É possível notar a rápida ascensão da curva que apresentou fase lag de aproximadamente 30 minutos ( $D O=0,22 \pm 0,011$ ), sendo acompanhada

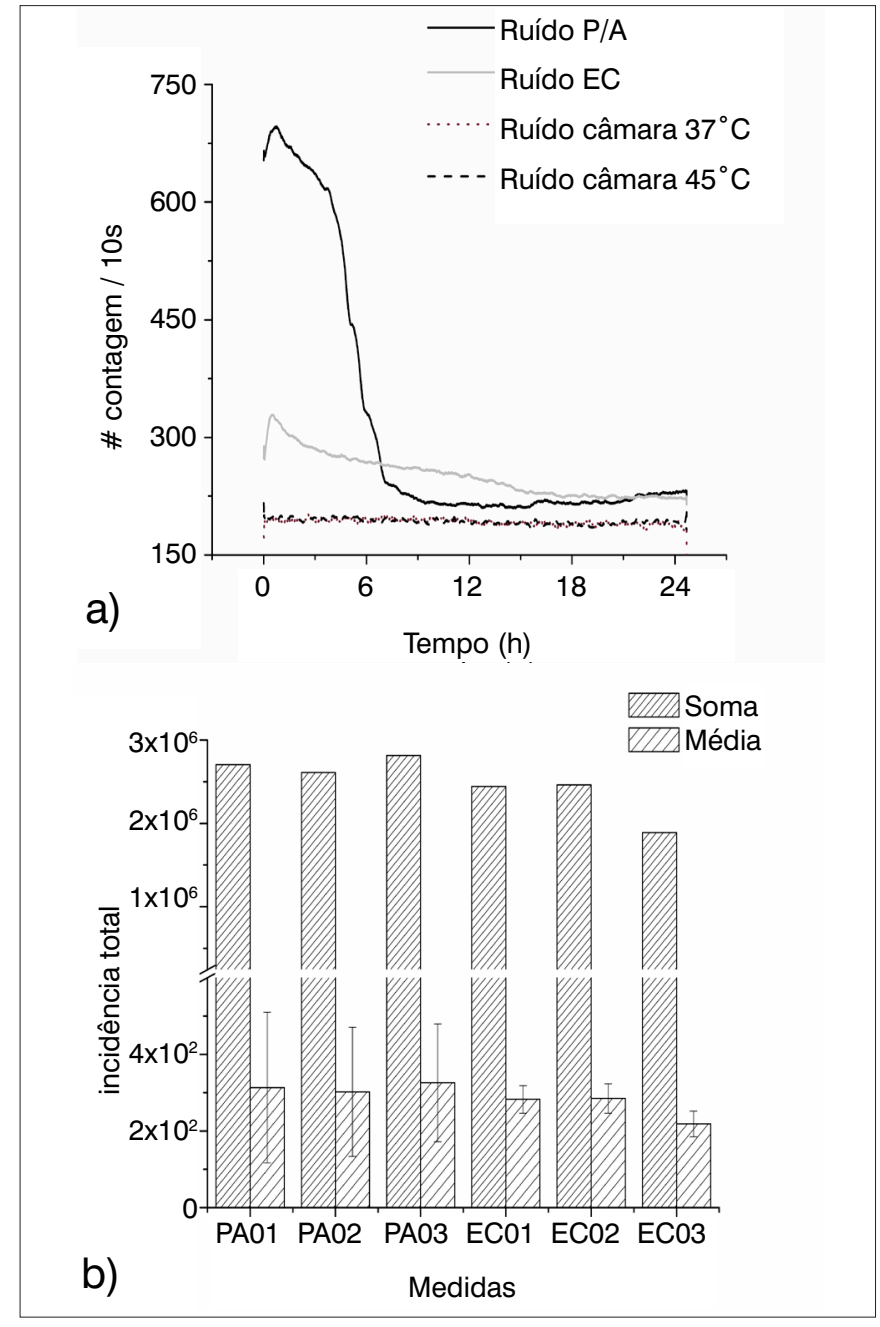

Figura 1 - Quimiluminescência proveniente dos meios de cultura P/A e EC: a) média dos 100 pontos locais; b) parâmetros estatísticos de três ensaios envolvendo fóton-contagem com base na soma, média e desvio padrão dos ensaios. posteriormente do crescimento exponencial pelo período de $4 \mathrm{~h}$ até a densidade ótica de $1,18 \pm 0,014$, iniciando a partir de então a estabilização da curva ( $\mathrm{DO}=1,2 \pm 0,014$ ), indicando assim o aparecimento da fase estacionária.

Os padrões de emissão de luz pela cepa em meio P/A seguiram, em parte, as mesmas características relatadas por Vogel e Süssmuth (1998a, 1999a), demonstrando menores incidências nas taxas de fóton-contagem em relação ao ruído do meio de cultura. Esses resultados podem estar associados com a capacidade dos micro-organismos em reduzirem o ruído do meio por meio de mecanismos que Popp e Klimek (2007) denominaram de "Photon Sucking". Analisando os perfis de emissão de luz, observa-se que os testes $\mathrm{t} 02$, $\mathrm{t} 03$, t04 e $\mathrm{t} 05$ apresentaram reprodutibilidade nos comportamentos, diferindo apenas do teste t01 que apresentou fóton-contagem média inicial maior que $700 \# / 10 \mathrm{~s}$, decaindo posteriormente à taxa média de 350 \#/10s até o período de 6 horas. Após esse comportamento, verifica-se que a curva se aproxima das demais. Durante a fase exponencial, observase o aparecimento de concavidades nas curvas pelo período de 45 minutos

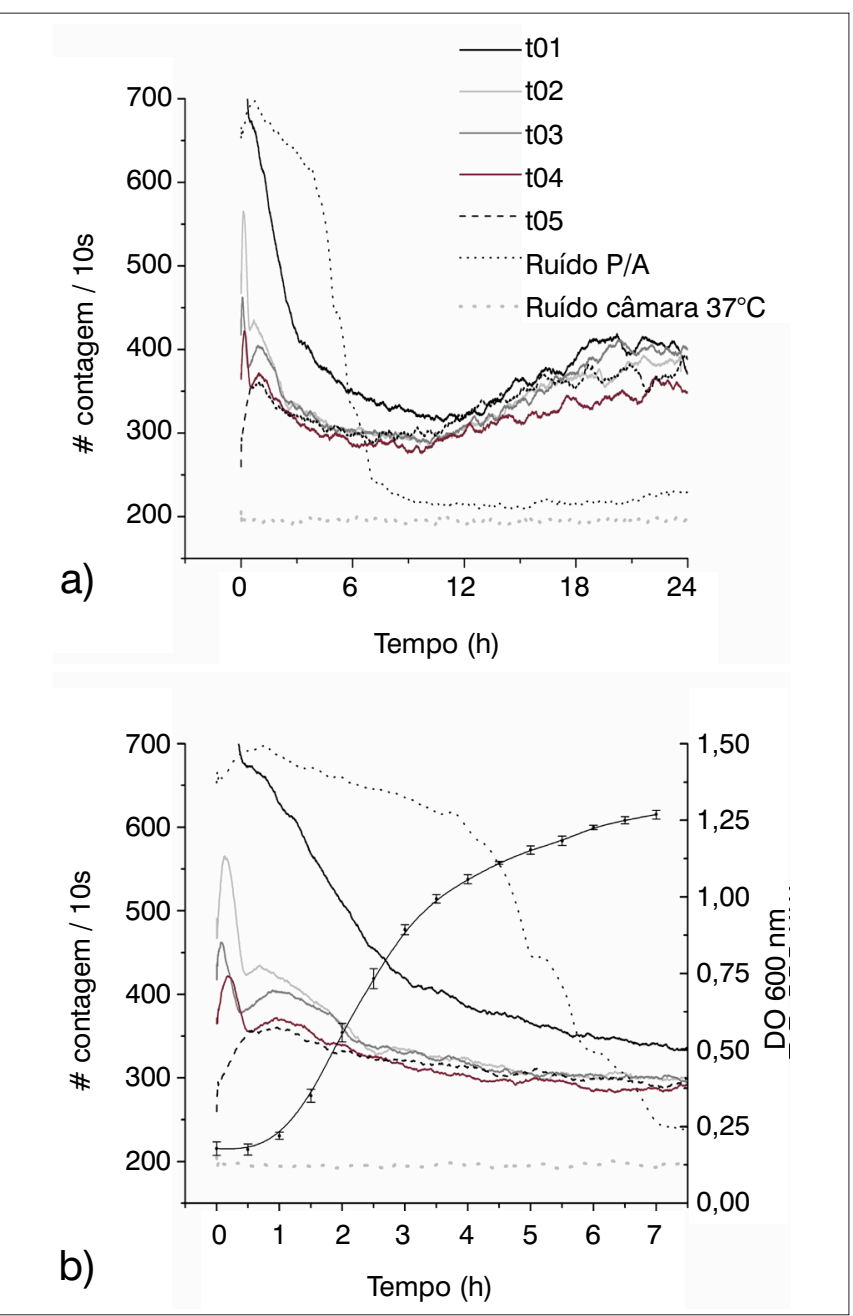

Figura 2 - Taxas de fóton-contagem de Escherichia coli em meio P/A com base na média dos 100 pontos locais (100\#): a) medidas de cinco ensaios efetuados com duração de $24 \mathrm{~h}$ de análise; b) ampliação das sete primeiras horas de ensaio comparando com as médias e desvios padrão da cinética de crescimento medida através da absorbância em espectrofotômetro. 
$(\mathrm{DO}=0,175 \pm 0,018)$ a 2,5 h com densidade ótica de 0,733 $\pm 0,032$. Em seguida, as taxas de fóton-contagem se estabilizam até cruzarem a curva do ruído e, a partir de então, nota-se o aumento das emissões de luz no sistema.

Por meio dos parâmetros de crescimento pôde-se obter a relação entre o desenvolvimento da cepa e a evolução das taxas de fóton-contagem ao longo do tempo. A Escherichia coli atingiu em média 5,78 gerações com desvios de $\pm 1,13$ gerações no intervalo de 7 horas de crescimento, com tempo de geração de $1,23 \pm 0,24 \mathrm{~h}$ e taxa de $0,82 \pm 0,16 \mathrm{~h}^{-1}$; todos esses parâmetros são acompanhados pela variação das taxas de fóton-contagem ao longo do tempo. Na Tabela 1 encontram-se as estimativas de Escherichia coli dos cinco testes realizados com densidade celular de $\sim 10^{10} \mathrm{NMP} / 100$ $\mathrm{mL}$, sendo possível verificar também a soma das fóton-contagens obtidas em cada teste e os valores mínimos e máximos ao longo de todo o experimento; nota-se que diferentes densidades de micro-organismos são acompanhados por diferentes taxas de fóton-contagem.

Comparando-se os cinco ensaios efetuados, nota-se o total de contagem apresentou um padrão da ordem de $10^{6} \# / 10$ s. As análises estatísticas dos experimentos controle demonstraram que em geral, os mínimos de fóton-contagem oscilaram entre 211 e 247 \#/10s, ao passo que as incidências máximas variaram em torno de 466 e 668 \#/10s, exceto no teste t01 que apresentou máximo de 1526 \#/10s.

Trushin (2003a) relatou comportamentos próximos aos aqui apresentados, com pequenas diferenças, pois aquele autor obteve taxa de crescimento de 0,769 $\pm 0,032 \mathrm{~h}^{-1}$ para Escherichia coli cultivada em meio LB. Já o tempo de geração foi de $1,357 \pm 0,088$ h quando a mesma cepa foi cultivada em meio M9, levando Trushin (2003b) a concluir que esses comportamentos são governados pela distribuição normal do ponto de vista estatístico.

Com o intuito de verificar relação entre o crescimento da cepa e a depleção de oxigênio dissolvido (OD) no meio, foram efetuadas medidas de OD ao longo das primeiras 6 horas de experimento, instante este em que a concentração atingiu o patamar próximo de zero. Os dados iniciais apresentaram valores médios de 2,70 $\pm 0,30 \mathrm{mg} \cdot \mathrm{L}^{-1}$, decaindo para 0,25 \pm 0,03 mg. $\mathrm{L}^{-1}$ após 2 horas de ensaio e chegando a 0,09 \pm 0,01 mg.L.-1, 6 horas após o início dos experimentos. Tal comportamento se assemelha também aos dados obtidos por Tilbury e Quickenden (1987a, 1987b) e Tilbury (1992). As observações desses autores evidenciam que existem duas fases características de fóton-contagem que envolve a fase exponencial de crescimento e a fase estacionária. $\mathrm{Na}$ fase exponencial ocorre o aparecimento de emissões que são acompanhadas por comprimentos de onda que variam de 210 a $330 \mathrm{~nm}$ e na região do visível (450 - $620 \mathrm{~nm}$ ), com intensidades diferindo em pequenas proporções. A fase estacionária compreende unicamente ao espectro visível com comprimentos de onda, variando também de 450 a $620 \mathrm{~nm}$.

Analisando em conjunto os dados de fóton-contagem na Figura 2 e os valores de oxigênio dissolvido, é possível atribuir duas regiões associadas à emissão de luz por Escherichia coli: uma delas em condições de aerobiose e outra associada a baixas concentrações de oxigênio. É sabido que a fase aeróbia permite a oxidação completa da glicose em dióxido de carbono, consumindo seis moléculas de oxigênio e produzindo 38 de moléculas adenosina trifosfato (ATP) (CARLSON; SRIENC, 2004). Na ausência de oxigênio, ocorre a fermentação da glicose com a produção de compostos como acetato, formato e lactato, em que a via anaeróbia com maior eficiência é capaz de produzir até três moléculas de ATP, uma de acetato e duas de formato por molécula de glicose fermentada, refletindo rendimento de aproximadamente 0,5 mol de ATP para cada mol de carbono de glicose consumida (CARLSON; SRIENC, 2004). Somando essas duas fases, os perfis biofotônicos são acompanhados pelas variações nas curvas ao longo das 24 horas de análise. Revela-se, dessa forma, o potencial da técnica biofotônica, que pode fornecer evidências dos comportamentos energéticos na obtenção e consumo de nutrientes pelos micro-organismos.

A comparação entre os padrões de emissão de luz nos ensaios controle com os dados descritos por Trushin (2003a) e Tilbury (1992), bem como a análise em conjunto dos padrões estatísticos de fóton-contagem e de crescimento do micro-organismo, permitiu a validação do método para que ensaios com efluente sanitário fossem efetuados.

\section{Comportamentos biofotônicos em amostras de esgoto sanitário}

Na Tabela 2 são apresentados os valores médios dos parâmetros físicos e químicos monitorados no esgoto bruto e tratado.

Os comportamentos biofotônicos envolvendo efluente sanitário apresentaram padrões de fóton-contagem semelhantes aos ensaios controle. No entanto, nos patamares de emissão foram observadas mudanças nos testes realizados com efluente bruto (Figura 3). Comparações efetuadas com os ensaios controle revelaram que em todas as amostras as taxas de emissão se elevaram acima do ruído do meio de cultura após seis horas do início dos ensaios, de forma semelhante aos comportamentos apresentados na série com densidade média de $10^{10} \mathrm{NMP} / 100 \mathrm{~mL}$ com Escherichia coli. Esse padrão foi observado tanto nos ensaios com efluente bruto como nos testes efetuados com efluente tratado.

A análise da estatística de fóton-contagem juntamente com as medidas das concentrações de OD no meio (variações de 0,40 a 4,00 mg.L-1 ${ }^{-1}$ ), revelaram que nos ensaios efetuados com maiores concentrações de oxigênio

Tabela 1 - Comparação entre os dados biofotônicos e a densidade celular de cinco réplicas experimentais envolvendo Escherichia coli em meio P/A

\begin{tabular}{|c|c|c|c|c|}
\hline Teste & Mínimo \#/10 s & Máximo \#/10 s & $\Sigma \# / 10 \mathrm{~s}$ & $\mathrm{NMP} / 100 \mathrm{~mL}$ \\
\hline t01 & 247 & 1526 & $3,27 \times 10^{6}$ & $8,80 \times 10^{10}$ \\
\hline t02 & 233 & 668 & $2,82 \times 10^{6}$ & $6,90 \times 10^{10}$ \\
\hline t03 & 217 & 543 & $2,83 \times 10^{6}$ & $1,00 \times 10^{12}$ \\
\hline t04 & 211 & 493 & $2,64 \times 10^{6}$ & $6,10 \times 10^{10}$ \\
\hline t05 & 221 & 466 & $2,76 \times 10^{6}$ & $9,00 \times 10^{10}$ \\
\hline
\end{tabular}


inicial, as curvas biofotônicas apresentaram decaimento mais rápido em relação aos testes com menores concentrações. Esse comportamento foi verificado nos testes t01 com OD inicial de 2,45 mg. $\mathrm{L}^{-1}$, na Figura 3a (esgoto bruto), nota-se que a curva de emissão de luz decresce rapidamente quando comparada com as demais. Já no teste t03, observa-se um tempo relativamente maior de queda da curva e o aparecimento de picos de emissão de luz. Ambos os ensaios foram seguidos pela variação na concentração dos micro-organismos conforme pode ser verificado na Tabela 3. Na Figura 3c (esgoto tratado) verifica-se que o comportamento foi semelhante, onde nos testes t01 e t03 com OD inicial igual a 6,65 e 5,72 mg. $\mathrm{L}^{-1}$, respectivamente, as curvas de emissão de luz decresceram rapidamente em relação aos testes t02 e t04.

Em média a concentração de OD final após 24 horas de ensaio foi de $0,21 \pm 0,02 \mathrm{mg} \cdot \mathrm{L}^{-1}$ refletindo diretamente no comportamento das curvas de fóton-contagem, ou seja, estas com incidências médias de 285 \#/10s. Comparando-se novamente estes comportamentos com aqueles obtidos nos ensaios controle, comprova-se que o oxigênio influencia na emissão de luz pelos micro-organismos. Contudo, mesmo para baixas concentrações de oxigênio, é possível detectar os fótons emitidos como comprovados nos experimentos.

Os padrões de emissão de luz no meio EC seguiram os apresentados no meio P/A, com incidências iniciais decaindo rapidamente até o nível de ruído, podendo isso, novamente, estar associado à capacidade dos micro-organismos em absorver o ruído do meio de cultura, como pode ser observado nos instantes $\mathrm{t}=1$ até $\mathrm{t}=6 \mathrm{~h}$. Posteriormente, as amostras apresentaram elevação nas taxas de fóton-contagem, mais intensamente nos ensaios efetuados com esgoto tratado (Figura 3d), onde a partir do momento em que a curva cruza o ruído em sentido ascendente, ocorre

Tabela 2 - Caracterização física e química do efluente sanitário

\begin{tabular}{|c|c|c|c|c|}
\hline \multirow{2}{*}{ Parâmetros físico-químicos } & \multicolumn{2}{|c|}{ Esgoto sem tratamento } & \multicolumn{2}{|c|}{ Esgoto pós-tratamento } \\
\hline & Média (mg. $\left.\mathrm{L}^{-1}\right)$ & Desvio padrão (mg. $\mathrm{L}^{-1}$ ) & Média (mg. $\left.\mathrm{L}^{-1}\right)$ & Desvio padrão (mg. $\left.\mathrm{L}^{-1}\right)$ \\
\hline $\mathrm{pH}$ & 8,23 & $\pm 0,37$ & 7,41 & $\pm 0,08$ \\
\hline OD & 2,28 & $\pm 1,80$ & 5,70 & $\pm 0,96$ \\
\hline $\mathrm{NH}_{3}$ & 43,06 & $\pm 6,31$ & 31,93 & $\pm 6,27$ \\
\hline $\mathrm{NO}_{3}^{3}$ & 0,40 & $\pm 0,60$ & 0,20 & $\pm 0,17$ \\
\hline $\mathrm{NO}_{2}^{3}$ & 2,00 & $\pm 3,46$ & 1,33 & $\pm 0,57$ \\
\hline$P^{-2}$ & 7,76 & $\pm 2,25$ & 2,08 & $\pm 0,16$ \\
\hline DQO & 215,62 & $\pm 104,58$ & 40,90 & $\pm 11,06$ \\
\hline
\end{tabular}

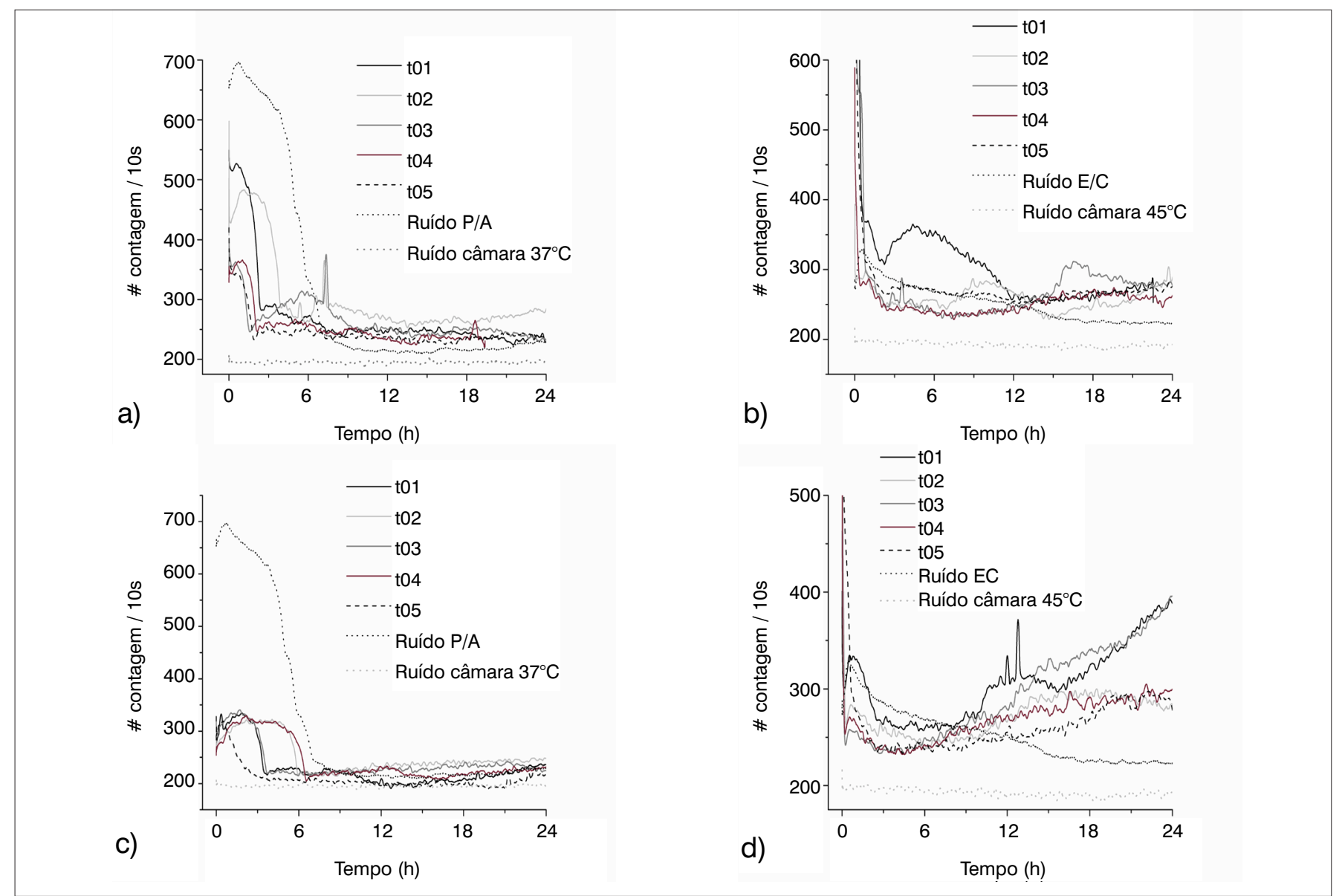

Figura 3 - Padrões de emissão de luz em meio P/A e meio EC: a) curvas biofotônicas com esgoto bruto incubados em meio P/A à 35,5C; b) incubação em meio EC com MUG a 44,5ㄷ para testes com Escherichia coli efetuada com amostra de esgoto positivada em meio P/A após 24h; c) comportamentos provenientes de esgoto tratado em meio P/A e d) amostras de esgoto positivadas incubadas em meio EC com MUG. 
elevação das taxas de fóton-contagem, partindo de 266 \#/10 s e elevandose até o final do experimento.

Investigações realizadas por Tilbury (1992) apontam que quando ocorre participação de oxigênio, este contribui para que a emissão de luz seja observada, pois mecanismos de reações de oxidação podem conduzir a emissão no espectro visível devido à decomposição de peróxidos lipídicos, processos de formação de estados eletronicamente excitados, conforme a Equação 1, em que o grupo carbonila ou o oxigênio podem formar tais estados.

$2>\mathrm{CHOO}$ à $>\mathrm{C}=\mathrm{O}+>\mathrm{COH}+\mathrm{O}_{2}$

Equação 1

Além da Equação 1, moléculas de oxigênio singleto podem contribuir para emissão secundária, em que um provável mecanismo de formação é descrito na Equação 2.

$>\mathrm{C}=\mathrm{C}<+\mathrm{O}_{2}\left({ }^{1} \mathrm{C}^{+}\right)$à $\mathrm{O}^{+}---\mathrm{O}^{+}$à $>\mathrm{C}=\mathrm{O}^{*}$

Equação 2

Outras evidências apontam para mecanismos envolvendo enzimas na cadeia respiratória de Escherichia coli na região da membrana que é rica em lipídeos. Essa riqueza associada à presença de moléculas de oxigênio singlete leva à decomposição de peróxidos lipídicos, conforme a Equação 1, que tendem a ser removidos pela reação com lipídeos insaturados, implicando a formação de grupos carbonilas excitadas conforme a Equação 2 (TILBURY, 1992).

A elevação da temperatura nos testes com meio EC provocou alterações no comportamento das curvas com Escherichia coli, sendo que as elevações das taxas de fóton-contagem se manifestaram nos testes com esgoto bruto e esgoto tratado (Figuras 3b e 3d). Essas mudanças de patamares de emissão de luz estão de acordo com experimentos efetuados por outros pesquisadores, que também encontraram variações nos padrões de fótoncontagem em função da temperatura (TILBURY; QHICKENDEN, 1987a, TILBURY, 1992).

Analisando os resultados apontados na Figura 3, e com base na soma do total de contagem disponíveis nas Tabelas 2 e 3, torna-se evidente que o processo de emissão de luz pode ser observado mesmo em baixas concentrações de oxigênio. Esse fato é elucidado, principalmente, com a cepa com densidade média de $10^{10} \mathrm{NMP} / 100 \mathrm{~mL}$, que consumiu rapidamente o oxigênio disponível no ensaio controle e, posteriormente, comprovado nos ensaios efetuados com esgoto bruto e esgoto tratado.

Obviamente, as mudanças de comportamento apresentadas nas séries com esgoto bruto e esgoto tratado estão relacionadas com a presença de micro-organismos no meio, pois as diferentes densidades de coliformes totais e Escherichia coli encontradas nessas amostras influenciaram diretamente nas conformações apresentadas pelas curvas de emissão de luz.

Foram constatadas correlações entre o crescimento de coliformes e as taxas de fóton-contagem. Observa-se que à medida que ocorre variação da densidade de coliformes, esta é acompanhada por diferentes taxas de fóton-contagem. Por exemplo, no teste t02 com esgoto bruto $\left(9,90 \times 10^{7}\right.$

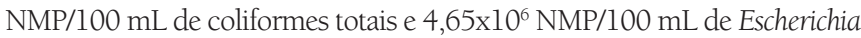
coli) e no ensaio t03 (com $6,83 \times 10^{7} \mathrm{NMP} / 100 \mathrm{~mL}$ coliformes totais e $1,00 \times 10^{7} \mathrm{NMP} / 100 \mathrm{~mL}$ de Escherichia coli) verifica-se que os comportamentos foram semelhantes.

\section{Conclusões}

A redução nas contagens de coliformes totais e Escherichia coli em amostras de esgoto bruto e tratado foi acompanhada pela variação nos padrões de emissão de luz.

Os resultados obtidos são interpretados como indicativos do potencial de aplicação dos fenômenos biofotônicos ao monitoramento de efluentes sanitários, com o emprego de técnicas de reposta rápida.

Sugere-se que tal potencial deva ser explorado em outras matrizes ambientais, tais como água bruta e água tratada para consumo humano.

\section{Agradecimentos}

Os autores são gratos à Fundação de Amparo à Pesquisa do Estado de São Paulo (Fapesp) (Processo 08/52821-0), à Coordenação de Aperfeiçoamento de Pessoal de Nível Superior (CAPES) e ao Fundo de Apoio ao Ensino, à Pesquisa e Extensão (Faepex) pelo financiamento da pesquisa. Cordiais agradecimentos são dados à Professora doutora Cassiana M. R. Coneglian pelo suporte laboratorial e sugestões no planejamento experimental.

Tabela 3 - Parâmetros biofotônicos com base na soma dos pontos totais e densidade de coliformes totais e Escherichia coli em amostras de esgoto sem e com tratamento

\begin{tabular}{|c|c|c|c|c|c|}
\hline Série de experimentos & Testes & $\begin{array}{c}\Sigma \# / 10 \text { s meio P/A } \\
37^{\circ} \mathrm{C}^{*}\end{array}$ & $\begin{array}{c}\Sigma \# / 10 \mathrm{~s} \\
\mathrm{EC}+\mathrm{MUG} 44,5^{\circ} \mathrm{C}^{*}\end{array}$ & $\begin{array}{l}\text { Coliformes totais }^{\star *} \\
\text { NMP/100 mL }\end{array}$ & $\begin{array}{c}\text { Escherichia coli** }^{*} \\
\text { NMP/100 mL }\end{array}$ \\
\hline \multirow{6}{*}{ Esgoto sem tratamento } & t01 & $2,33 \times 10^{6}$ & $2,43 \times 10^{6}$ & $1,58 \times 10^{7}$ & $5,20 \times 10^{6}$ \\
\hline & t02 & $2,60 \times 10^{6}$ & $2,19 \times 10^{6}$ & $9,09 \times 10^{7}$ & $4,65 \times 10^{6}$ \\
\hline & t03 & $2,27 \times 10^{6}$ & $2,31 \times 10^{6}$ & $6,83 \times 10^{7}$ & $1,00 \times 10^{7}$ \\
\hline & t04 & $2,32 \times 10^{6}$ & $2,31 \times 10^{6}$ & $1,75 \times 10^{7}$ & $5,20 \times 10^{6}$ \\
\hline & t05 & $2,11 \times 10^{6}$ & $2,14 \times 10^{6}$ & $1,71 \times 10^{7}$ & $4,10 \times 10^{6}$ \\
\hline & Ruído & $1,88 \times 10^{6}$ & $1,81 \times 10^{6}$ & 0,00 & 0,00 \\
\hline \multirow{6}{*}{ Esgoto com tratamento } & t01 & $1,97 \times 10^{6}$ & $2,67 \times 10^{6}$ & $1,45 \times 10^{6}$ & $1,08 \times 10^{6}$ \\
\hline & t02 & $2,17 \times 10^{6}$ & $2,34 \times 10^{6}$ & $2,04 \times 10^{4}$ & $1,00 \times 10^{4}$ \\
\hline & t03 & $2,07 \times 10^{6}$ & $2,57 \times 10^{6}$ & $1,31 \times 10^{6}$ & $9,60 \times 10^{5}$ \\
\hline & t04 & $2,09 \times 10^{6}$ & $2,32 \times 10^{6}$ & $1,85 \times 10^{5}$ & $3,10 \times 10^{4}$ \\
\hline & t05 & $1,81 \times 10^{6}$ & $2,28 \times 10^{6}$ & $5,20 \times 10^{4}$ & $2,00 \times 10^{4}$ \\
\hline & Ruído & $1,90 \times 10^{6}$ & $1,85 \times 10^{6}$ & 0,00 & 0,00 \\
\hline
\end{tabular}

**Medidas efetuadas com substrato cromogênico paralelamente aos ensaios conforme APHA (1998). 


\section{Referências}

AGUDO, E. G. Guia de coleta e preservação de amostras de água. CETESB, São Paulo, 1988. 150 p.

ANEJA, K. R. Experiments in microbiology, plant pathologyand biotechnology. 3. ed. New York New Age International, 2004. p. 214-218.

APHA. Standard Methods for the Examination of Water and Wastewater. 20. ed. American Public Health, Washington Dc, 1998. 1134 p.

BELOUSSOV, L. V.; VOEIKOV, V. L.; MARTYNYUK, V. S. Biophotonics and Coherent Systems in Biology. New York: Springer, 2007. 306 p.

BISCHOF, M. Biophotons-the light in our cells. Journal of Optometric Phototherapy, p. 1-5, 2005

BUDAGOVSKY, A. V. On the ability of cells to distinguish the coherence of optical radiation. Quantun Eletronics, v. 35, p. 369-374, 2005.

CARLSON, R.; SRIENC, F. Fundamental Escherichia coli Biochemical Pathways for Biomass and Energy Production: identification of reactions. Biotechnology and Bioengineering, v. 85, n. 1, p. 1-19, 2004.

CHANG, J. J.; FISCH, J.; POPP, F. A. Biophotons. Netherlands: Kluwer Academic Publishers, 1998. $413 p$.

FELS, D. Cellular communication through light. PLOS ONE, v. 4, n. 4, p. 1-8, 2009.

GALLEP, C. M.; SANTOS, A. M. O.; CONFORTI, E. Low-cost, simplified systems for photon-counting measurements in biological samples. In: International microwave and optoelectronics conference imoc, Anais, p. 188- 191, 2005

LAAGER, F. M.; BECKER, N. M.; PARK, S. H.; SOH; K. S. Effects of lac operon activation, deletion of the yhha gene, and the removal of oxygen on the ultra-weak photon emission of Escherichai coli. Electromagnetic Biology and Medicine, v. 28, p. 240-249, 2009.

LEE, J. Y.; DEININGER, R. A. Detection of Escherichia coli in beach water within 1 hour using immunomagnetc separation and ATP bioluminescence. Luminescence, p. 31-36, 2004.

MADIGAN, M. T.; MARTINKO, J. M.; PARKER, J. B. Biology of Microorganisms, 10. ed., Upper Saddle River, Pearson Education. p. 137-166, 2003. Cap 6,

MATHEW, F. P.; ALAGESAN, D.; ALOCIJA, E. C. Chemiluminescence detection of Escherichia coli in fresh produce obtained from different sources. Luminescence, v. 19, p. 193-198, 2004.

NIKOLAEV, Y. A. Distant Interactions in Bacteria. Microbiology, v. 69, n. 5, p. 497-503, 2000a

NIKOLAEV, Y. A. Role of Distant Interactions in the Regulation of the Adhesion of Pseudomonas fluorescens Cells. Microbiology, v. 69, n. 3, p.291-295, 2000b.

POPP, F. A. Biophoton Background, experimental results, theorical approach and applications. Photochemistry \& Photobiology, v. 1, p. 31-40, 2000.
POOP, F. A.; KLIMEK, W. Photon Sucking as an Essential Principal of Biological Regulation. Biophotonics and Coherent Systems in Biology. New York: Springer, 2007. 306p.

RAHN, O. Invisible radiations of organisms. Berlin, Verlag von Gebrüder Borntraeger, 1935. 209 p.

RODA, A.; PASINI, P.; MIRASOLI, M.; MICHELINI, E.; GUARDIGLI, M Biotechnological applications of bioluminescence and Chemiluminescence. Trendds in Biotechnology, v. 22, n. 6, p. 295-303, 2004.

TRUSHIN, M. V. Studies on distant regulation of bacterial growth and light emission. Microbiology, v. 149, p. 363-368, 2003a.

TRUSHIN, M. V. Culture-to-culture physical interactions causes the alteration in red and infrared light stimulation Escherichia coli growth rate. J. Microbiol. Immunol Infect, v. 36, p. 149-152, 2003b.

TRUSHIN, M. V. The possible role of eletromagnetic fields in bacterial communication. Journal of Microbiology Immunology and Infection, v. 36 , p. 153-160, 2003c

TRUSHIN, M. V. Do bacterial cultures spread messages by emission of eletromagnetic radiations? Annals of Microbiology, v. 53, p. 37-42, 2003d.

TRUSHIN, M. V. Light-mediated "conversation" among microorganisms. Microbiological Reserch, v. 159, p. 1-10, 2004.

TILBURY, R. N.; QUICKENDEN, T. I. The Effect of Cosmic-Ray Shielding on the Ultraweak Bioluminescence Emitted by Cultures of Escherichia coli. Radiation Research, v. 112, p. 398-402, 1987.

TILBURY, R. N.; QUICKENDEN, T. I. Spectral and time dependence studies of the ultraweak bioluminescence emitted by the bacterium Escherichia coli. Photochemistry And Photobiology, v. 47, n. 1, p. 145-150, 1988.

TILBURY, R. N. The effect of stress factor on the spontaneous photon emission from microorganisms. Experientia, v. 48, p. 1030-1040, 1992.

VOGEL, R.; GUO, X.; SÜSSMUTH, R. Chemiluminescence patterns from bacterial cultures undergoing bacteriophage induced mass lysis. Bioeletrochemistry and Bioenergetics, v. 46, p. 59-64, 1998.

VOGEL, R.; SÜSSMUTH, R. Interaction of bacterial cells with weak light emission from culture media. Bioeletrochemistry and Bioenergetics, v. 45 p. 93-101, 1998a.

VOGEL, R.; SÜSSMUTH, R. Involvement of the cell membrane in chemiluminescence patterns from bacterial cultures. Bioeletrochemistry and Bioenergetics, v. 46, p. 65-69, 1998b.

VOGEL, R.; SÜSSMUTH, R. A model for the generation of low level chemiluminescence from microbiological growth media and its depletion by bacterial cells. Bioeletrochemistry and Bioenergetics, v. 48, p. 375-382, 1999a.

VOGEL, R.; SÜSSMUTH, R. Weak light emission patterns from lactic acid bacteria. Luminescence, v. 14, p. 99-105, 1999b. 